\title{
LA LIBERTAD DE CREACIÓN Y PRODUCCIÓN CIENTIIFICA: ESPECIAL REFERENCIA A LA LEY DE INVESTIGACIÓN BIOMÉDICA
}

YOLANDA GÓMEZ SÁNCHEZ 


\section{SUMARIO}

1. EL DERECHO FUNDAMENTAL A LA LIBERTAD DE INVESTIGACIÓN Y PRODUCCIÓN CIENTÍFICA. 2. GARANTÍAS Y LÍMITES DE LA INVESTIGACIÓN CIENTÍFICA 3. LA LEY DE INVESTIGACIÓN BIOMÉDICA COMO LEY ORDINARIA 4. LEY DE INVESTIGACIÓN BIOMÉDICA. 4.1. Objeto y ámbito de aplicación. 4.2. Principios de la Ley de Investigación Biomédica. 4.3. Libertad e igualdad: los principios ausentes. 


\title{
LA LIBERTAD DE CREACIÓN Y PRODUCCIÓN CIENTÍFICA: ESPECIAL REFERENCIA A LA LEY DE INVESTIGACIÓN BIOMÉDICA
}

POR

\author{
YOLANDA GÓMEZ SÁNCHEZ \\ Catedrática de Derecho Constitucional \\ UNED
}

\section{EL DERECHO FUNDAMENTAL A LA LIBERTAD DE INVESTIGACIÓN, PRODUCCIÓN Y CREACIÓN CIENTÍFICA}

La incorporación de un amplio y pormenorizado catálogo de derechos y libertades es, sin duda, una de las características más notables de la Constitución española y un factor sustancial para la transformación social y jurídica que se ha operado en España a partir de su vigencia. Desde este elenco constitucional se ha construido un sistema de derechos y garantías del que se puede afirmar, sin riesgo a error, que es el de mayor amplitud y eficacia en la historia de nuestro país. Tanto los derechos civiles y políticos clásicos como los derechos económicos, sociales y de prestación, alumbrados en torno a las dos grandes Guerras Mundiales, tuvieron acogida en el Texto Fundamental de 1978. No ha sucedido lo mismo con los derechos de cuarta generación ${ }^{1}$ que dan cobijo a los nuevos dere-

${ }^{1}$ Sobre los nuevos derechos biotecnológicos de cuarta generación pueden consultarse mis trabajos: Derechos Constitucional Europeo, Sanz y Torres, Madrid, 2005, pág. 60 y sigs.; «Biotecnología y derechos fundamentales», Constitución y Democracia. 25 años de Constitución Democrática en España, Centro de Estudios Políticos y Constitucionales/Universidad del País Vasco, 2 vols., Bilbao, 
chos tecnológicos en general y biotecnológicos en particular. Esta ausencia, explicada más por las razones políticas de la Transición que por el momento cronológico en el que se redactó la Constitución, nos obliga a residenciar — cuando ello es técnicamente posible - nuevas demandas sociales en viejos derechos y a integrar en el contenido esencial de éstos los emergentes problemas derivados del imponente dinamismo de la investigación y producción científica actual que demandan la atención inexcusable del ordenamiento jurídico.

No hay en la Constitución española una referencia directa y explícita a la investigación biomédica ni encontramos tampoco en el Texto Fundamental referencias a otros problemas derivados de estas nuevas biotecnologías. Sí contiene la Constitución, sin embargo, referencias directas a la investigación en general (arts. 44.2, 148.1.17 y 149.1.15); y ha reconocido, como derecho fundamental, la producción y creación científica en el artículo 20.1.b). Este artículo, dedicado a la protección de la libertad de expresión, el derecho a la información y otros derechos derivados o complementarios de los anteriores, consagra literalmente el derecho fundamental $~ A$ la producción y creación literaria, artística, científica y técnica».

El complejo artículo 20 de la Constitución ha sido ampliamente estudiado desde muy diferentes enfoques y son muy diversas las opiniones sobre los derechos que en él se regulan. En lo que respecta a la creación científica podemos entender por tal aquella actividad humana que desvela e incorpora al conocimiento general, una idea, un hecho o un elemento o interrelaciona ideas, hechos o elementos ya conocidos aportando una novedad sobre el estado anterior del conocimiento. El término producción parece aludir más a la generación, fabricación o articulación de cosas o materiales y, por extensión, a la producción intelectual, destinados directamente a aplicaciones prácticas. Con todo, el apartado b) del artículo 20.1 no alude expresamente a la investigación científica que, en puridad, no es producción ni creación; la investigación sería el proceso previo y necesario tanto para la creación como para la producción científica, consistente en las diligencias para descubrir algo o en la realización de actividades intelectuales o experimentales de modo sistemático con el propósito de modificar los conocimientos sobre una determinada materia o asunto. De modo muy sintético podríamos decir que la investigación es el trabajo; la creación el resultado y la producción la aplicación práctica y la transferencia de conocimientos.

2005, vol. 1, págs. 223 y sigs.; Pasado, presente y futuro de los Derechos Humanos, GÓMEZ SÁNCHEZ, Y. (Coord.), CNDH/UNED, Madrid-México; «El derecho de autodeterminación física como derecho de cuarta generación", en BRENA SESMA, I. (Coord.): Panorama Internacional en Salud y Derecho, Instituto de Investigaciones Jurídicas de la UNAM, México, 2007, págs. 205 y sigs. 
Debería haberse incluido expresamente en el artículo 20.1 b) de la Constitución una referencia a la investigación, tanto más cuando, el artículo $44.2 \mathrm{CE}$, asigna a los poderes públicos la promoción de la misma y los artículos 149.1. 15 y 148.1.17 la mencionan a los efectos del reparto competencial entre el Estado y las Comunidades Autónomas. Con todo, la ausencia expresa de este término en el artículo 20.1.b) CE, no significa que la investigación científica no forme parte del contenido esencial del derecho consagrado en el mencionado precepto. No resultaría jurídicamente convincente que el contenido esencial a la producción y creación científica no incorporara la fase previa e insoslayable -la investigación- a través de la cual se obtienen prácticamente la totalidad de los resultados de producción y creación científica. No se trata, pues, de defender que la investigación es lo mismo que la producción o creación científica, sino que en ámbito material de protección definido en el artículo 20.1b), está comprendida la investigación como parte del contenido esencial del derecho protegido en este precepto. El Tribunal Constitucional ha afirmado que el derecho a la producción y creación científica, artística y técnica es una concreción del derecho a expresar y difundir libremente pensamientos, ideas y opiniones (ST 153/1985, de 7 de noviembre), lo que debe implicar el derecho a realizar los actos necesarios para conseguir tal fin, con los límites que pudieran ser aplicables a otros derechos y libertades.

Por su parte, el mencionado artículo 44.2 CE, dentro del Capítulo III, del Título I, dedicado a los principios de política social y económica, establece que los «poderes públicos promoverán la ciencia y la investigación científica y técnica en beneficio del interés general»; y el también citado artículo 149.1.15 asigna la competencia exclusiva al Estado, entre otras, del «Fomento y coordinación general de la investigación científica y técnica», competencia que debe hacerse compatible con la que el artículo 148.1.17 atribuye a las Comunidades Autónomas, en relación también con el fomento de la cultura y de la investigación. El Tribunal Constitucional se ha pronunciado en diferentes ocasiones sobre el alcance y articulación de estas competencias en nuestro actual Estado descentralizado (entre otras, SSTC 53/1988, 90/1992 y 186/1999), de manera que la competencia exclusiva del Estado no llega a excluir actividades de las Comunidades Autónomas en orden al fomento y promoción de la investigación científica. La competencia del Estado se ha plasmado en la aprobación de la Ley 13/1986, de 14 de abril, de Fomento y Coordinación General de la Investigación Científica y Técnica y, en razón de sus competencias, diferentes Comunidades Autónomas han aprobado también leyes en esta materia ${ }^{2}$.

${ }^{2}$ Entre otras, Ley 5/1998, de 7 de mayo de Fomento de la Investigación Científica y la Innovación Tecnológica de Madrid; Ley 7/1997, de 9 de diciembre, de Fomento y Coordinación de 
Otras leyes han venido a regular aspectos complementarios a la investigación, tal como la Ley de la Propiedad Intelectual ${ }^{3}$, que garantiza al sujeto la atribución del resultado obtenido y, en caso necesario, su defensa; o la Ley de Patentes ${ }^{4}$, que completa la protección de las actividades investigadoras a través de la tutela de las aplicaciones prácticas. En ambos casos, estas normas han incorporado las correspondientes Directivas comunitarias sobre estas materias.

Sí encontramos una regulación específica sobre investigación científica en el ámbito de la enseñanza superior en la Ley Orgánica 6/2001, de 21 de diciembre, de Universidades. El artículo 39 de la Ley Orgánica sobre «La investigación y la transferencia del conocimiento. Funciones de la universidad", proclama que la «investigación científica es el fundamento esencial de la docencia y una herramienta primordial para el desarrollo social a través de la transferencia de sus resultados a la sociedad» (apartado 1); para afirmar a continuación que se «reconoce y garantiza la libertad de investigación en el ámbito universitario» (apartado 2) y concluir que la universidad tiene como uno de sus objetivos esenciales el «desarrollo de la investigación científica, técnica y artística y la transferencia del conocimiento a la sociedad, así como la formación de investigadores e investigadoras, y atenderá tanto a la investigación básica como a la aplicada».

Con todo, hasta la aprobación de la Ley de Investigación Biomédica (LIB) no había en España una norma que abordara globalmente los problemas derivados de las investigaciones en este específico campo aunque sí había prece-

la Investigación Científica y del Desarrollo Tecnológico de la Comunidad Valenciana; Ley 3/1998, de 16 de marzo, de Investigación y Desarrollo Tecnológico de La Rioja; Ley 4/1999, de 17 de marzo, de Investigación y Ciencia de Castilla y León; Ley de la Comunidad Autónoma de Canarias 5/2001, de 9 de julio, de Promoción y Desarrollo de la Investigación Científica y la Innovación; Ley 17/2002, de 19 de diciembre, de Fomento y Coordinación General de la Investigación Científica, Desarrollo e Innovación Tecnológica (I + D + I) en Castilla y León; Ley 9/2003, de 12 de marzo, de fomento y coordinación de la investigación, el desarrollo y transferencia de conocimientos en Aragón; Ley 8/2007, de 23 de abril, de Fomento y Coordinación de la Investigación Científica, el Desarrollo Tecnológico y la Innovación de la Comunidad Autónoma de la Región de Murcia.

${ }^{3}$ Real Decreto Legislativo 1/1996, de 12 de abril por el que se aprobó el Texto Refundido de la Ley de Propiedad Intelectual (modificada posteriormente).

${ }^{4}$ Ley 11/1986, de 20 de marzo, de Patentes (modificada posteriormente).

5 Tal es el caso del Capítulo IV de la Ley 16/2003, de 28 de mayo de Cohesión y calidad del Sistema Nacional de Salud y, también, de la hoy derogada Ley 35/1988, de 22 de noviembre sobre Técnicas de Reproducción Asistida; la Ley de la Comunidad Autónoma de Andalucía 7/2003, de 20 de octubre, por la que se regula la investigación en Andalucía con preembriones humanos no viables para la fecundación in vitro; el Real Decreto 223/2004, de 6 de febrero, por el que se regulan los ensayos clínicos con medicamentos (transposición de la Directiva Europea 2001/20/EC) 
dentes en la regulación de aspectos concretos 5 . La Ley 14/2007, de 3 de julio, viene, pues, a cubrir una necesidad de regulación en materias muy sensibles por su vinculación e implicaciones en los derechos fundamentales y, especialmente, reúne en una norma jurídica los aspectos esenciales de la investigación en Biomedicina. Con esta Ley, España confirma su decidida apuesta por crear un conjunto normativo que discipline las aplicaciones y consecuencias de los nuevos avances científicos en el marco del respeto a los derechos y libertades fundamentales. Las implicaciones de la Biomedicina precisan de una respuesta jurídica acorde con su intensidad; el nuevo Bioderecho — del que esta Ley de Investigación Biomédica forma parte- está llamado a regular tales situaciones que afectan tanto a los particulares, como a instituciones públicas y agentes privados. Del certero enfoque de estas normas y de su inexcusable ubicación en el marco constitucional dependerá que la investigación biomédica logre objetivos tangibles en el campo de la salud, la calidad y las expectativas de vida de los ciudadanos sin merma del libre ejercicio de sus derechos fundamentales.

De otro lado, la tendencia tanto de los textos constitucionales como de los documentos supranacionales en orden a regular los nuevos avances científicos y, específicamente, aspectos relevantes de las nuevas biotecnologías, es muy evidente. La Constitución de Suiza ha incorporado diversos artículos sobre reproducción asistida o trasplante de órganos; la Constitución de Portugal ha consagrado el novedoso derecho a la identidad genética y las Constituciones de Hungría, Lituania, Estonia, Polonia y Bulgaria han constitucionalizado diversos derechos biomédicos, como el consentimiento informado o la prohibición de experimentación en humanos sin previo e informado consentimiento ${ }^{6}$. En el ámbito supranacional europeo deben destacarse los trabajos del Consejo de Europa y, en especial, la aprobación del Convenio sobre Biomedicina y Derechos Humanos y sus Protocolos Adicionales sobre Prohibición de Clonación Humana; sobre Trasplantes de Órganos y Tejidos de Origen Humano7; y sobre Investigación Biomédica ${ }^{8}$. También en el ámbito europeo, la Unión Europea ha aprobado un número importante de documentos, aunque de diferente naturaleza ju-

o la derogada Ley 42/1988, de 28 de diciembre sobre donación y utilización de embriones y fetos humanos, de sus células, tejidos y órganos.

${ }^{6}$ Sobre este punto puede consultarse mi trabajo: «El derecho de autodeterminación física como derecho de cuarta generación", en Panorama Internacional en Salud y Derecho, BRENA SESMA, I. (coord.), ob cit.

24 de enero de 2002.

830 de junio de 2004. Resulta evidente la influencia que este Protocolo ha tenido en la redacción de la Ley de Investigación Biomédica que comentamos. 
rídica, sobre aspectos biotecnológicos ${ }^{9}$. La Carta de Derechos Fundamentales, proclamada en el Consejo Europeo de Niza de 2000, incluyó un importante artículo $3^{10}$, bajo el rótulo "Derecho a la integridad de la persona» en el que, en su apartado 2, se explicita el derecho a la integridad respecto de las aplicaciones biomédicas y se consagra el consentimiento libre e informado; la prohibición de las prácticas eugenésicas; la prohibición de que el cuerpo humano o partes del mismo en cuanto tales se conviertan en objeto de lucro y la prohibición de la clonación reproductora de seres humanos.

Resulta igualmente obligado citar en este punto los trabajos de la UNESCO y, en especial, la aprobación de sus tres Declaraciones sobre aspectos relativos a la Biomedicina y los Derechos Humanos ${ }^{11}$. El primer logro del Programa de Bioética de la UNESCO fue la aprobación de la Declaración Universal sobre el

${ }^{9}$ Especial relevancia tienen la Directiva 93/41/CEE del Consejo de 14 de junio de 1993 por la que se deroga la Directiva 87/22/CEE por la que se aproximan las medidas nacionales relativas a la comercialización de medicamentos de alta tecnología, en particular los obtenidos por biotecnología; la Directiva 98/44/CE del Parlamento Europeo y del Consejo de 6 de julio de 1998 relativa a la protección jurídica de las invenciones biotecnológicas o la Directiva 2001/18/CE del Parlamento Europeo y del Consejo, de 12 de marzo de 2001, sobre la liberación intencional en el medio ambiente de organismos modificados genéticamente.

${ }^{10}$ La Carta constituyó la Parte II de la malograda Constitución Europea. El Tratado de Lisboa ha incluido la previsión de que la Carta adquirirá el mismo valor jurídico de los Tratado a través de la reforma del artículo 6 del Tratado de la Unión Europea que tiene ahora la siguiente redacción: «La Unión reconoce los derechos, libertades y principios enunciados en la Carta de los Derechos Fundamentales de la Unión Europea de 7 de diciembre de 2000, tal como fue adoptada el 12 de diciembre de 2007 en Estrasburgo, la cual tendrá el mismo valor jurídico que los Tratados.

Las disposiciones de la Carta no ampliarán en modo alguno las competencias de la Unión tal como se definen en los Tratados.

Los derechos, libertades y principios enunciados en la Carta se interpretarán con arreglo a las disposiciones generales del título VII de la Carta por las que se rige su interpretación y aplicación y teniendo debidamente en cuenta las explicaciones a que se hace referencia en la Carta, que indican las fuentes de dichas disposiciones.

...."

11 Sobre las aportaciones de la UNESCO en este campo, pueden consultarse los diversos trabajos de Héctor GROS ESPIELL, entre ellos: «Las Declaraciones de la UNESCO en materia de Bioética, Genética y Generaciones futuras, su importancia y su incidencia en el desarrollo del Derecho Internacional», en BENÍTEZ ORTÚZAR, I., MORILLAS CUEVA, L., PERIS RIERA, J.: Estudios jurídico-penales sobre genética y biomedicina, Dykinson, Madrid, 2005, pág. 21 y sigs.; «Naturaleza jurídica de la Declaración Universal. Su importancia e incidencia en el desarrollo del Derecho Internacional», en GROS ESPIELL, H., GÓMEZ SÁNCHEZ, Y.: La Declaración Universal sobre Bioética y Derechos Humanos de la UNESCO, Comares, Granada, 2006, pág. 211 y sigs. 
Genoma y los Derechos Humanos en 1997 a la que siguió la adopción de la Declaración Internacional de Datos Genéticos Humanos en 2003 y, en 2005, la aprobación de la Declaración Universal de Bioética y Derechos Humanos. Con estas tres Declaraciones la UNESCO ha consolidado una importante línea de trabajo en el ámbito internacional con una doble consecuencia: por un lado, las Declaraciones adoptadas han articulado unos principios y líneas de actuación principalmente para los Estados aunque también para organizaciones, asociaciones y grupos profesionales ${ }^{12}$ que manifiestan el consenso internacional en estas importantes materias y, por otro lado, son textos prospectivos para aquellos países que no han abordado una regulación en estas materias. En ambos casos la trascendencia de plasmar unos principios generales y unas directrices en tan relevantes asuntos no deja de ser un hecho que merece ser destacado.

\section{GARANTÍAS Y LIIMITES DE LA INVESTIGACIÓN CIENTÍFICA}

Como venimos defendiendo la investigación científica participa de las garantías reconocidas al artículo 20.1.b) de la Constitución. El desarrollo de los derechos que en este párrafo se consagran requiere, de conformidad con el artículo 81.1 CE, ley orgánica y reciben las máximas garantías jurisdiccionales a través de un procedimiento preferente y sumario y, subsidiariamente, mediante recurso de amparo ante el Tribunal Constitucional (art. 53. CE). El propio artículo 20 incorpora una garantía concreta para los derechos regulados en dicho artículo. Así establece, en el apartado 2, que ninguno de los derechos consagrados en este precepto podrá ser limitado por ningún tipo de censura previa, aunque, correlativamente, establece también como límites específicos de los derechos del artículo 20, el respeto a los derechos reconocidos en este Título I de la Constitución, en los preceptos de las leyes que lo desarrollen y, especialmente, en el derecho al honor, a la intimidad, a la propia imagen y a la protección de la juventud y de la infancia.

En materia de investigación biomédica la garantía de la prohibición de censura previa no puede ser interpretada con el mismo alcance que lo es en materia de producción intelectual. Bien es verdad, que dicha garantía permite la li-

${ }_{12}$ Me he referido al valor normativo internacional de las Declaraciones de la UNESCO, en especial, de la Declaración Universal sobre Bioética y Derechos Humanos en «Autonomía, igualdad y no discriminación como principios fundamentales de la Declaración Universal», en GROS ESPIELL, H., GÓMEZ SÁNCHEZ, Y.: La Declaración Universal sobre Bioética y Derechos Humanos de la UNESCO, ob. cit. 
bre producción y creación científica y, por ende, también la libertad de investigación, pero su alcance no es tal que impida requerir una autorización previa para la realización de determinadas investigaciones. Antes al contrario, esta es la situación más común. El requisito de autorización previa no puede llegar a consistir en una suerte de censura sobre la futura actividad sino que debe desenvolverse en los términos de un control previo de legalidad que garantice que la investigación que se pretende realizar es acorde con la legislación aplicable.

Por otro lado, los límites establecidos en el apartado 4 del artículo 20 vienen a confirmar que todos los derechos constitucionales pueden tener límites ${ }^{13}$. El Tribunal Constitucional declaró muy tempranamente que no existen en el ordenamiento español «derechos ilimitados. Todo derecho tiene sus límites» ${ }^{14}$, manifestación que ha sido repetida en numerosas sentencia del Alto Tribunal. Esta idea de la limitación de los derechos, responde a la pretensión de que el reconocimiento de un derecho no lleve, de facto, a una situación de abuso o de uso antisocial del mismo ${ }^{15}$ y permite, también, avalar la tesis de que para que todos los derechos reconocidos puedan ser ejercitados ninguno de ellos puede ser ilimitado. La doctrina, de manera casi unánime y siguiendo la jurisprudencia constitucional, ha defendido el carácter limitado de los derechos: los derechos deben articularse en un sistema en el que sea posible el ejercicio de todos ellos, lo cual sólo es factible, como ya se señaló, aceptando que pueden tener límites.

El Tribunal Constitucional, en una de sus iniciales sentencias, la 11/1981, de 8 de abril, señaló que los límites de los derechos no quedan circunscritos a los que expresamente contenga el Texto constitucional y a los que derivan del libre ejercicio de unos y otros derechos reconocidos en la Constitución, sino que también hay límites mediatos, sólo indirectamente emanados de la Constitución pero necesarios para preservar otros derechos o bienes constitucionalmente protegidos. Dijo entonces el Tribunal Constitucional que no podía aceptarse la tesis «de que los derechos reconocidos o consagrados por la Constitución sólo pueden quedar acotados en virtud de límites de la propia Constitución o por la necesaria acomodación con el ejercicio de otros derechos reconocidos y declarados igualmente por la Norma Fundamental». La Constitución -añadió el Tribunalestablece por sí misma los límites de los derechos fundamentales en algunas ocasiones; en otros casos, el límite del derecho deriva de la Constitución sólo de una

${ }^{13}$ Sobre este punto, puede consultarse mi trabajo: Derecho Constitucional Europeo: derechos y libertades, ob. cit., pág. 134 y sigs.

14 STC 2/1982, de 29 de enero.

15 Recordemos, en este sentido, que el Código Civil (art. 7.2), afirma que «La ley no ampara el abuso del derecho o el ejercicio antisocial del mismo». 
manera mediata o indirecta, en cuanto ha de justificarse por la necesidad de proteger o preservar no sólo otros derechos constitucionales, sino también otros bienes constitucionalmente protegidos». En la citada sentencia el Tribunal afirmó también que la "Constitución es un marco de coincidencias suficientemente amplio para que dentro de él quepan opciones política de muy diferente signo»; y que, en consecuencia, corresponde «al legislador ordinario regular con mayor o menor generosidad las condiciones de ejercicio de un derecho siempre que no pase más allá de los límites impuestos por las normas constitucionales, límites que existen siempre y que, en ocasiones, se establecen sólo de modo mediato o indirecto».

Dentro de estos parámetros debe interpretarse el alcance de la investigación biomédica; como derecho faculta a los investigadores y a los profesionales biomédicos para el ejercicio libre de la misma y a los sujetos para participar en ella, pero unas y otras actividades deben desenvolverse en el estricto marco de los derechos y libertades fundamentales establecidos en la Constitución y del resto del ordenamiento jurídico. La Ley de Investigación Biomédica se ahorma a este marco jurídico y en sus artículos 1.1 y 2 a) somete su objeto — la regulación de la investigación científica - al pleno respeto a la dignidad e identidad humanas y a los derechos inherentes a la persona y garantiza a toda persona, sin discriminación alguna, el respeto a la integridad y a sus demás derechos y libertades fundamentales.

\section{LA LEY DE INVESTIGACIÓN BIOMÉDICA COMO LEY ORDINARIA}

La Ley 14/2007, 3 de julio, partió de un proyecto de ley presentado por el Gobierno en el Congreso de los Diputados el 15 de septiembre de 2006, calificado el 19 de septiembre de ese mismo año como ley ordinaria y así tramitado hasta su aprobación final. La aplicación de este tipo normativo a la Ley sobre Investigación Biomédica suscita algunas dudas de las que trato a continuación.

La Disposición final primera de la LIB afirma que la aprobación de dicha Ley se realiza al amparo de la competencia exclusiva en materia de fomento y coordinación general de la investigación científica y técnica y en materia de bases y coordinación general de la sanidad de conformidad con lo establecido en el artículo $149.1 .15^{\mathrm{a}}$ y $16^{\mathrm{a}}$. Pero no estamos ante una ley sólo de promoción o de fomento de la investigación (la LIB sólo dedica el artículo 10 a regular específicamente y con carácter general la promoción y calidad de la investigación científica) y/o de coordinación general de la sanidad. La Ley de Investigación 
Biomédica no es comparable a la Ley 13/1986, de 14 de abril, sobre Fomento y Coordinación General de la Investigación Científica y Técnica dictada por el Estado al amparo de la competencia atribuida en el mencionado artículo 149.1.15, o de las aprobadas en diversas Comunidades Autónomas en base a la competencia establecida en el artículo 148.1.17.

En este caso, la Ley sobre Investigación Biomédica regula realmente una parte del contenido esencial del derecho fundamental consagrado en el artículo 20.1.b) al que ya antes he aludido. La propia Ley, en su artículo 1.1, así lo establece al afirmar que su objeto es «regular, con pleno respeto a la dignidad e identidad humanas y a los derechos inherentes a la persona, la investigación biomédica» $y$, en particular, las que en el mismo artículo se mencionan específicamente. De igual manera, el artículo 2 d) establece que la Ley garantiza «la libertad de investigación y de producción científica en el ámbito de las ciencias biomédicas». Desde el propio Preámbulo se manifiesta que uno de los ejes prioritarios de la Ley es «asegurar el respeto y la protección de los derechos fundamentales y las libertades públicas del ser humano y de otros bienes jurídicos relacionados con ellos»; que se fundamenta en la libre autonomía de la persona de la que se derivan los derechos específicos a otorgar el consentimiento y a obtener la información previa y que, desde el punto de vista de la acción investigadora, la Ley garantiza la «libertad de investigación y de producción científica en los términos del artículo 20 de nuestra Constitución».

En coherencia con estas manifestaciones, la Ley de Investigación Biomédica regula pormenorizadamente derechos de los sujetos que participan en una investigación pero también se refiere a los derechos y obligaciones de los profesionales biomédicos. Este segundo aspecto es, en realidad, el desarrollo directo del derecho a la investigación, creación y producción científica consagrado en el reiterado artículo 20.1 b) de la Constitución del cual derivan un conjunto de consecuencias jurídicas que son contempladas a lo largo del articulado de la Ley.

Esta Ley, como he señalado, afecta a otros derechos fundamentales como el derecho a la libertad o el derecho a la intimidad al adentrarse en materias como la protección de datos, el deber de confidencialidad, el consentimiento informado o las intervenciones sobre seres humanos. La jurisprudencia constitucional (entre otras, SSTC 15/1985 y 116/1999, de 17 de junio) excluyó al embrión como sujeto del derecho a la vida reconocido en el artículo $15 \mathrm{CE}$, por lo que la cuestión no se centra en este precepto pero sí en otros derechos fundamentales de la Sección $1^{\text {a }}$ del Capítulo II $^{16}$.

${ }^{16}$ También y previamente STC 53/1985 y 212/1996, de 19 de diciembre. 
La Ley de Investigación Biomédica es especialmente sensible a todos los aspectos relativos a la protección de la confidencialidad y los datos de carácter personal regulando aspectos concretos y señalando a la Ley Orgánica 15/1999, de 13 de diciembre, de Protección de Datos de Carácter Personal como supletoria en las cuestiones no reguladas en ella (Disposición final segunda). No deja de resultar paradójico que se considerara necesaria la ley orgánica para aprobar la Ley de Protección de Datos y no reciban igual tratamiento jurídico los datos y la regulación de la confidencialidad que se contiene en la Ley de Investigación Biomédica. En igual sentido cabría pronunciarse respecto a la regulación relativa a las manifestaciones de libertad del sujeto ante diversas acciones biomédicas reguladas en esta ley, las cuales traen su fundamento en el derecho a la libertad regulado en el artículo 17.1 de la Constitución ${ }^{17}$ y, por ende, merecedoras del tipo normativo de ley orgánica. Con todo, especialmente significativo es el caso de la regulación de la investigación científica en la Ley Orgánica 6/2001, de 21 de diciembre, de Universidades, regulada en el Título VII (artículos 39 a 41). En este Título de la Ley Orgánica solo se ha excluido de dicho carácter orgánico el artículo 41, que se refiere al fomento de la investigación, del desarrollo científico y de la innovación tecnológica en la Universidad en coherencia con el reparto competencial entre el Estado y las Comunidades Autónomas al que antes ya he hecho referencia. Los dos primeros artículos - 39 y 40 - que se refieren a la investigación científica sí tienen carácter orgánico. No se acaban aquí los ejemplos aunque resulta igualmente evidente que no todo el contenido de los noventa artículos de que se compone de esta Ley es materia de ley orgánica.

En todo caso, esta Ley de Investigación Biomédica desarrolla, como ya hemos señalado anteriormente, una parte del contenido esencial del derecho fundamental consagrado en el mencionado artículo $20.1 b$ ) y solo por ello debería haberse tramitado y aprobado como una ley orgánica, o al menos, algunos de sus preceptos deberían haber tenido esta naturaleza. Si a ello sumamos la incidencia directa de determinados artículos en el desarrollo de otros derechos fundamentales ya antes citados, la adecuación del procedimiento parlamentario de la ley ordinaria a esta norma resulta altamente discutible. Lo más correcto jurídicamente hubiera sido utilizar la técnica mediante la cual —en una disposición fi-

17 He venido defendiendo reiteradamente que en el contenido esencial del derecho fundamental a la libertad consagrado en el apartado 1, del artículo 17, están incluidas las decisiones de la persona respecto de su propia realidad física. No puedo extenderme en estas páginas sobre los argumentos que me llevan a mantener esta tesis. Sobre el particular, pueden consultarse mis trabajos: El derecho a la reproducción humana, Marcial Pons, Madrid, 1994; "El derecho de autodeterminación física como derecho de cuarta generación", en BRENA SESMA, I.: Panorama Internacional en Salud y Derecho, ob. cit., pág. 205 y sigs. 
nal- se hubieran hecho constar los artículos de naturaleza orgánica o, alternativamente, los artículos de naturaleza ordinaria si la Ley se hubiera publicado bajo el tipo normativo de ley orgánica. En uno u otro caso, ello hubiera obligado obviamente a la tramitación parlamentaria — procedimiento de ley orgánica o procedimiento de ley ordinaria - que hubiera correspondido a los diferentes artículos de la Ley. Los artículos orgánicos de la Ley habrían consolidado este procedimiento - no jerarquía - de manera que su modificación o derogación, de conformidad con lo establecido en el artículo $81 \mathrm{CE}$, hubieran requerido las mismas mayorías reforzadas que su aprobación. Esto hubiera sido más preciso y ajustado a Derecho aunque, en algún punto, hubiera resultado más difícil obtener las mayorías parlamentarias reforzadas que requiere la ley orgánica.

\section{LA LEY DE INVESTIGACIÓN BIOMÉDICA}

\subsection{Objeto y ámbito de aplicación}

Como ya he señalado al referirme al tipo normativo de la Ley de Investigación Biomédica, el artículo 1.1 establece nítidamente el objeto de esta norma que no es otro que regular la investigación biomédica, con pleno respeto a la dignidad e identidad humanas y a los derechos inherentes a la persona. He manifestado también que la investigación biomédica es una parte de la investigación científica y que ésta forma parte del contenido esencial del derecho protegido en el artículo 20.1.b) de la Constitución. El apartado primero del artículo 1 de la Ley sobre Investigación Biomédica no hace sino señalar el ámbito material de la regulación contenida en ella y la interrelación y ponderación que debe existir entre el derecho consagrado en el artículo 20.1.b) y los demás derechos que se citan, en concreto, la dignidad, la identidad y los derechos inherente a la persona.

La mención de la dignidad es ya clásica en las leyes y documentos internacionales sobre cuestiones biomédicas y biotecnológicas. Prácticamente todos los documentos supranacionales que abordan estos temas se fundamentan en la dignidad humana y en los demás derechos y libertades que hoy se consideran inherentes a dicha dignidad. Estados, con muy diferentes sistemas jurídicos y valores sociales, han esgrimido la dignidad como el baluarte desde el que regular los problemas biomédicos y consolidar un estándar mínimo de protección de la libertad y de la igualdad del ser humano.

También la Ley de Investigación Biomédica sigue esta línea en los mencionados artículos 1.1 y 2 a). La redacción del primero de ellos está claramente inspirado en el también artículo 1.1 del Convenio sobre Biomedicina y Derechos 
Humanos $^{18}$, en lo que se refiere a la mención de la dignidad e identidad del ser humano aunque el Convenio añade que garantizará a toda persona, sin discriminación alguna, el respeto a su integridad y a los demás derechos y libertades fundamentales, expresión que la Ley de Investigación Biomédica incluye en otro precepto, en concreto en el artículo 2. a).

En la definición de su objeto, pues, Ley de Investigación Biomédica no menciona los derechos y libertades fundamentales sino los derechos inherentes a la persona lo cual podría no tener el mismo alcance jurídico. En una interpretación estricta, estos derechos inherentes de la persona serían aquellos mencionado junto a la dignidad- en el artículo 10.1 de la Constitución (fuera de la sección $1^{\text {a }}$, del capítulo II, del título I), que, sin embargo, la Constitución no relaciona. Estimo que los derechos inherentes citados en el artículo 10.1 CE no son otros sino los que la propia Constitución consagra a lo largo del Título I. Es decir, que no hay derechos inherentes fuera de la Constitución ni hay derechos constitucionales que no sean inherentes a la persona, especialmente en relación con el estándar europeo actual de derechos y libertades. Cabría otra interpretación conforme a la cual los derechos inherentes serían aquéllos directamente relacionados con el ser humano (vida, integridad, ....), si bien esta tesis no es fácilmente deducible de la Constitución y no aporta mayores garantías a la persona. Por todo ello, creo que debe hacerse una interpretación integrada de los artículos 1.1 y 2 a) y entender que el objeto de la ley no desconoce el respeto a los derechos fundamentales sino que los mismos están incluidos entre los derechos inherentes a los que se alude en el artículo 1.1 de la Ley.

Complementariamente a la definición general del objeto de la Ley, el artículo 1.1 especifica siete ámbitos particulares sobre los que se proyecta el objeto de la Ley. Con estas menciones específicas, la Ley delimita aspectos concretos y refuerza la importancia de los mismos en el contexto de la investigación biomédica. Estos ámbitos son:

a) Las investigaciones relacionadas con la salud humana que impliquen procedimientos invasivos, lo cual no significa que las investigaciones en humanos que no tengan este carácter queden excluidas de la ley; unas y otras son objeto de regulación en la misma.

18 También los Protocolos del Convenio aluden a la dignidad, identidad y a los Derechos Humanos o derechos fundamentales, tal es el caso del Protocolo Adicional sobre Prohibición de Clonación Humana; el Protocolo Adicional sobre Trasplantes de Órganos y Tejidos de Origen Humano y el Protocolo Adicional sobre Investigación Biomédica. Otros muchos textos supranacionales aluden igualmente a la dignidad, así arts. 1 y 2 a) de la Declaración Universal del Genoma y los Derechos Humanos; art. 1 a) de la Declaración Internacional de Datos Genéticos Humanos y art. 2 c) de la Declaración Universal de Bioética y Derechos Humanos. 
b) La donación y utilización de ovocitos, espermatozoides, preembriones, embriones y fetos humanos o de sus células, tejidos u órganos con fines de investigación biomédica y sus posibles aplicaciones clínicas. En este sentido, el Protocolo Adicional al Convenio sobre Biomedicina y Derechos Humanos, sobre Investigación Biomédica, excluye, en su artículo 2.2, de su ámbito de aplicación la investigación con embriones in vitro, exclusión que no figura en la Ley española. La inclusión de esta materia en la Ley de Investigación Biomédica permite la derogación de la Ley 42/1988, de 28 de diciembre, de donación y utilización de embriones y fetos humanos, de sus células, tejidos y órganos como efectivamente se hace en la Disposición derogatoria única.

c) El tratamiento de muestras biológicas y su almacenamiento y movimiento. Como más adelante se señala, el artículo 2 c) de la Ley consagra el principio de respeto a los derechos y libertades fundamentales, la garantía de la confidencialidad en el tratamientos de los datos en este ámbito. El artículo 11, por su parte, regula lo relativo a la entrada y salida de muestras biológicas y el Título $\mathrm{V}$ pormenoriza la regulación sobre las mismas.

d) Los biobancos, definidos en la Ley como los «establecimientos públicos o privados, sin ánimo de lucro, que acoge una colección de muestras biológicas concebida con fines diagnósticos o de investigación biomédica y organizada como una unidad técnica con criterios de calidad, orden y destino» (art. 3), regulados en detalle en el Capítulo IV del Título V de la Ley, al que ya hemos hecho referencia anteriormente.

e) El Comité de Bioética de España cuya regulación específica se encuentra en el Título VII de la Ley y los demás órganos con competencias en materia de investigación biomédica.

f) Los mecanismos de fomento, promoción, planificación, evaluación y coordinación de la investigación biomédica. El artículo 10 de la Ley sienta los principios para el fomento y promoción de la investigación biomédica que son desarrollados a lo largo del articulado y en especial, para el Sistema Nacional de Salud, en Título VIII de la LIB.

En cuanto al ámbito territorial de la Ley, su contenido es aplicable a todo el territorio, sin perjuicio de la competencia que las Comunidades Autónomas tienen reconocida en el artículo 148.1.17 ya aludido anteriormente y de su facultad para adoptar las medidas necesarias para garantizar la efectividad de esta Ley; facultad que también asiste al Estado (Disposición final primera) al que igualmente corresponde la competencia de desarrollo reglamentario de conformidad con la Disposición final tercera. 
En cuanto al ámbito de aplicación, la Ley sobre Investigación Biomédica señala con bastante nitidez sus contornos. La regla general es que la LIB extiende su ámbito de aplicación sobre cualquier investigación biomédica, incluida la investigación de carácter básico y la clínica, de conformidad con el art. 1.3 y tanto para el sector privado como para el sector público, aunque con las excepciones que la propia Ley señala. Por un lado, circunscribe materias determinadas a ámbitos concretos como es el caso del artículo 1.2 en el que se alude, como parte del objeto de la ley, a la regulación de los análisis genéticos y el tratamiento de datos genéticos de carácter personal exclusivamente dentro del ámbito sanitario. Por otro lado, excluye de su ámbito la regulación de los ensayos clínicos con medicamentos y productos sanitarios que se rigen por su normativa específica (art. 1.3) $)^{19}$ las implantaciones de órganos, tejidos y células de cualquier origen, cuya regulación sigue sujeta a la Ley 30/1979, de 27 de octubre, sobre extracción y trasplante de órganos y normas complementarias (art. 1.4).

\subsection{Principios de la Ley de Investigación Biomédica}

El artículo 2 de la Ley, con el rótulo general de «Principios y garantías de la investigación biomédica» y partiendo de la afirmación del sometimiento de la investigación biomédica a las garantías que en dicho precepto se detallan, lo que realmente contiene es un conjunto de principios rectores o principios generales de actuación en el ámbito de la investigación biomédica. El hecho de que alguno de estos principios manifieste que se garantiza o se debe garantizar un derecho, otro principio o un interés legítimo, no lo convierte en una garantía jurídica, las cuales deben articulan y hacen posible una tutela normativa, jurisdiccional o institucional. Por ello, el rótulo del artículo podría haber aludido solamente a "principios» o, quizá, a "principios generales». Los artículos 4 a 12 del Título I en el que igualmente se encuentra ubicado el artículo 2, completan el elenco de principios que rigen la Ley; tal es el caso del consentimiento informado (art. 4); confidencialidad y protección de datos (art. 5); trazabilidad y seguridad (art. 8); límites de análisis genéticos (art. 9); y de los Comités de Ética de la Investigación (art. 12), todos los cuales tienen un desarrollo pormenorizado a lo largo de la Ley y encuentran en estos iniciales artículos, como ya he señalado, su posición como principios rectores o de actuación. Por otro lado, es importante señalar que algunos de los principios contenidos en este precepto de la LIB son verda-

19 Real Decreto 223/2004, de 6 de febrero, por el que se regulan los ensayos clínicos con medicamentos. 
deros derechos fundamentales que, sin embargo, adoptan aquí la forma de principios aun sin perder su naturaleza de derechos (tal es el caso de la confidencialidad, la protección de datos o de la prohibición de discriminación).

La distinción entre el concepto de principios y el de garantías no es tema menor en el ámbito jurídico. Los principios enunciados no admiten jerarquía; representan los valores fundamentales en los que la norma se apoya o, también, las grandes líneas organizativas que estructuran una institución. La ley, a partir de los principios que incorpore, debe articular el resto de su contenido, es decir, los principios están en una relación de causa-efecto respecto del resto del contenido de la norma. No puede afirmarse que toda norma cumpla con este paradigma pero sí que ello es inexcusable para poder afirmar la coherencia de la misma. Una de las obligaciones del jurista es detectar en qué medida los principios enunciados en una norma se plasman a lo largo del articulado o si, por el contrario, los principios proclamados son vulnerados o desconocidos por el propio texto ${ }^{20}$. De otra parte, las garantías articulan la tutela y defensa de los derechos, bienes y situaciones jurídicas mediante procedimientos normativos, jurisdiccionales o institucionales.

Trataremos a continuación, pues, de los principios $^{21}$ (llamados garantías) contenidos en el artículo 2 y analizaremos a continuación otros preceptos que integran el Título I de la Ley de Investigación Biomédica ${ }^{22}$.

La Ley de Investigación Biomédica establece en el mencionado artículo 2 siete diferentes principios aplicables a cualquier investigación biomédica que se realice al amparo de esta norma:

1) Principio de respeto de la dignidad e identidad del ser humano, de su integridad y de los demás derechos y libertades fundamentales en cualquier investigación que implique intervenciones con seres humanos (art. 2 a). Con una redacción algo confusa la LIB establece este primer principio de la investigación biomédica. Efectivamente, de la redacción de este precepto parece desprenderse que se protege la dignidad e identidad del ser humano y se garantiza el respeto a la integridad y a los demás derechos y libertades fundamentales; no hay auténticos derechos sin garantías; en este sentido, cabría afirmar que no cabe proteger sin

${ }^{20}$ No puedo, sin embargo, extenderse sobre este problema que excede del contenido de este trabajo.

${ }^{21}$ La Ley de Investigación Biomédica deroga los apartados 5 y 6 del artículo 45 y los artículos 46 y 47 de la Ley 16/2003, de 28 de mayo de cohesión y calidad del Sistema Nacional de Salud que regulaba lo relativo a la investigación en salud, aunque mantiene vigente el artículo 44 que se refiere a los principios de la investigación (Disposición derogatoria única de la LIB).

${ }^{22}$ No son objeto de este trabajo, el análisis de los artículo 3, 11 y 12. 
garantía ni garantizar sin protección. La interpretación que cabe dar a este primer apartado del artículo 2, no es otra sino que la Ley sobre Investigación Biomédica adopta como principio rector la protección y garantía de la dignidad, de la identidad, de la integridad y de los demás derechos y libertades fundamentales de la persona, y, también, no fundamentales, es decir, que también irradia su ámbito sobre derechos constitucionales como el derecho a la protección de la salud (art. 43.1 CE). No cabe otra interpretación cuando la propia Constitución establece un estricto sistema garantista para los derechos y libertades en ella reconocidos.

El reconocimiento de la dignidad y los derechos fundamentales de la persona está presente en los más relevantes documentos supranacionales sobre la materia ${ }^{23}$. Los conceptos de dignidad y autonomía están estrechamente vinculados y una correcta interpretación integrada de ambos avala la tesis de la indisponibilidad de la persona, la cual no está sujeta a la discrecionalidad del Estado ni de la sociedad, ni sus derechos pueden ceder ante pretendidos intereses de aquél o de ésta. La dignidad y la libertad de la persona determinan que deba ser reconocida como sujeto y no como objeto de los acontecimientos y de las situaciones $^{24}$. Sin embargo, como más adelante se explica, la Ley de Investigación Biomédica no incluye la libertad personal entre los principios que comentamos.

De otra parte, el reconocimiento de la libertad de la persona no es sino la expresión de un derecho de autodeterminación fisica ${ }^{25}$ cuya existencia vengo defendiendo desde hace ya más de una década y que, progresivamente, va tomando cuerpo en diferentes textos legales e instrumentos internacionales. El derecho de autodeterminación fisica ${ }^{26}$ define un ámbito de agere licere, un haz de facultades,

${ }^{23}$ Así, entre otros varios, art. 1 del Convenio sobre Biomedicina y Derechos Humanos; art. 1 de su Protocolo Adicional sobre Investigación Biomédica; art. 2 de la Declaración Universal del Genoma y los Derechos Humanos; art. 1 a) de la Declaración Internacional sobre Datos Genéticos Humanos; art. 3 de la Declaración Universal de Bioética y Derechos Humanos.

${ }_{24}$ Sobre la dignidad humana puede consultarse, entre otros, ANDORNO, R.: «La dignidad humana como noción clave en la Declaración de la UNESCO sobre el genoma humano», Revista de Derecho y Genoma Humano, 2001, n 14, p. 41-53; "Dignity of the person in the light of international biomedical law», Medicina e Morale, 2005, n 1, p. 91-105.

${ }^{25}$ En 1994 tuve la oportunidad de defender la existencia del derecho de autodeterminación fisica, en una de sus manifestaciones concretas: el derecho a la reproducción humana: GÓMEZ SÁNCHEZ, Y.: El derecho a la reproducción humana, ob. cit.

${ }^{26}$ Mi posición respecto de este nuevo derecho de autodeterminación fisica, puede consultarse en: "Biotecnología y derechos fundamentales», en Constitución y democracia. 25 años de Constitución democrática en España, ob. cit.; "El derecho de autodeterminación física como derecho de cuarta generación", en BRENA SESMA, I. (Coord.): Panorama internacional en salud y derecho, ob. cit. 
de libertad decisoria protegida por el ordenamiento, que permite a la persona decidir, optar o seleccionar qué hacer o no hacer respecto de todas aquellas cuestiones y situaciones que afecten a su realidad física, a su sustrato corporal. La autodeterminación física es el poder de cada persona para decidir sobre su propia vida, sus valores y dirigir su destino.

El reconocimiento de este derecho permite ordenar de manera adecuada las relaciones entre el sujeto y el poder, pero también entre aquél y personas, instituciones y grupos con los que precise relacionarse por cuestiones que afecten a opciones sobre su vida física o su salud. Este derecho entrega al sujeto el poder de decisión sobre sí mismo lo cual resulta no sólo acorde con el ejercicio de su derecho a la libertad sino también con las exigencias de la dignidad que forma parte del standard de derechos reconocido en numerosos países y en el ámbito internacional. Que todo ello deba realizarse en un contexto de respeto a los derechos de los demás y a los valores y principios democráticos no hace sino confirmar la tesis de la complementariedad de los derechos fundamentales y la interpretación integrada y, en su caso, ponderada que debe presidir su aplicación.

2) Principio de primacía de la salud, el interés y el bienestar del ser humano sobre el interés de la sociedad o de la ciencia. Este principio está ampliamente recepcionado en diversos documentos supranacionales aunque con matices de redacción no exentos, sin embargo, de interés. Así el artículo 2 del Convenio sobre Biomedicina y Derechos Humanos y el artículo 3.2 de la Declaración Universal sobre Bioética y Derechos Humanos establecen la primacía del ser humano sobre el «exclusivo» interés de la sociedad o la ciencia. En todo caso, viene este principio a definir una jerarquía de valores: en caso de conflicto, la persona antes que la investigación. Ya hemos señalado que la investigación científica está consagrada en España como un derecho fundamental por ello resulta relevante que la Ley fije expresamente que los objetivos y fines de la investigación - aun siendo legítimos y mereciendo una protección del ordenamiento jurídicono pueden prevalecer sobre la salud, el interés y el bienestar de la persona que, así enunciados, no son derechos fundamentales pero los representan. Los conceptos de interés y bienestar de la persona deben ser reconducidos a los derechos fundamentales de ésta (derecho a la vida, a la integridad, a la libertad, a la igualdad, a la intimidad ....). De otra parte, la articulación jurídica de los diferentes derechos y bienes constitucionalmente protegidos no se plantea tanto en términos de exclusión sino de ponderación y equilibrio entre ellos; es en esta ponderación donde el bienestar del ser humano podría llegar a prevalecer sobre otros intereses sociales o científicos. Jurídicamente este principio de primacía se 
manifiesta como un límite al derecho fundamental de investigación biomédica de manera que resultarían justificadas las limitaciones que pudieran establecerse para garantizar este principio sin llegar a desnaturalizar el derecho a la investigación o hacerlo impracticable.

De otra parte, el rechazo a la instrumentalización de las personas está permitiendo delimitar ámbitos positivos de protección, ámbitos de inmunidad, tanto en el ámbito internacional como en el de los ordenamientos nacionales. Ello es especialmente evidente en relación con el ámbito de la biomedicina donde el principio de no instrumentalización ha sido consagrado en tratados y declaraciones internaciones y ha tenido reflejo también en la legislación de desarrollo de algunos países ${ }^{27}$.

3) Principio de respeto a la confidencialidad y protección de datos en la investigación con muestras biológicas, en especial, en la realización de análisis genéticos. Como ya antes he señalado, uno de los ejes sobre los que pivota la Ley de Investigación Biomédica es el respeto a la confidencialidad y a la protección de datos como manifestación, entre otros, del derecho a la intimidad que la Constitución reconoce en su artículo 18.1. En coherencia con ello, uno de los principios enunciados en el artículo 2 es el de la confidencialidad y la protección de datos en las investigaciones a partir de muestras biológicas, en especial, en lo referente a la realización de análisis genéticos. Como en otros casos, la especificación a la que se alude en este principio no excluye que el mismo se proyecte en general sobre todo tipo de investigación biomédica regulada en la Ley y así está reflejado a lo largo de su articulado (arts. 5, 8, 12 h), 15 d), 42.2, 45 b), 50.1, 51, 53, 58.2 e) 59.1 h) 70.1, 74.2 B) d), 81.3.c) y Disposición Transitoria Segunda). Trataremos de este aspecto en un epígrafe posterior.

4) Principio de libertad de investigación y de producción científica en el ámbito de las ciencias biomédicas. Estamos en este caso ante un derecho fundamental enunciado como principio de actuación, lo cual no resulta incompatible con la Constitución siempre que no se pretenda rebajar la naturaleza jurídica del tal derecho fundamental a una previsión de carácter general. Por otro lado, no resulta tampoco inconveniente que este principio acote su ámbito al contexto material de las ciencias biomédicas. Como corresponde al ámbito material de la Ley, las referencias a la investigación biomédica son abundantísimas a lo largo

27 En España, encontramos menciones a la dignidad de la persona, entre otros documentos, en el Preámbulo y en el artículo 2.1 y 9.5 de la Ley 41/2002, de 14 de noviembre, básica reguladora de la autonomia del paciente y de derechos y obligaciones en materia de información y documentación clinica. 
del texto y es, como señala Preámbulo y el artículo 1.1 de la Ley, el objeto de la misma, tal y como ya se expuso en un epígrafe anterior.

5) Principio de previo y preceptivo informe favorable del Comité de Ética de la Investigación para la autorización y desarrollo de los proyectos de investigación con seres humanos. La emergencia y progresiva implantación de Comités de Ética (y/o Bioética $)^{28}$ en el ámbito de la práctica clínica e investigadora parte de su reconocimiento en el ámbito supranacional. La Declaración de Helsinki abordó la necesidad de crear organismos que colaborasen con los profesionales biomédicos en el control de la calidad de los protocolos de investigación para proteger a los seres humanos lo que dio lugar a la progresiva aparición de los Comités de Ensayos Clínicos. Actualmente los Comités de Ética (o Bioética) son de distinta naturaleza y asumen también competencias diversas. La Ley de Investigación Biomédica crea un Comité de Ética de la Investigación que opera en los centros que realicen investigación biomédica y que deberán estar acreditados por el órgano competente de la Comunidad Autónoma que corresponda o por el órgano competente de la Administración General del Estado cuando dependan de ésta.

Como ya señalé anteriormente, el derecho fundamental consagrado en el artículo 20.1b) CE, y su garantía específica de prohibición de censura previa, no impide que, en los casos de proyectos de investigación biomédica con seres humanos, se pueda someter a autorización previa que, sin embargo, debe ceñirse a la constatación de que el proyecto reúne y cumple los requisitos establecidos en la legislación española y respeta los derechos fundamentales de las personas. De conformidad con el artículo 12 de la Ley, el Comité de Ética de la Investigación evaluará la cualificación de los investigadores, la viabilidad del proyecto; ponderará los aspectos metodológicos, éticos y legales del proyecto de investigación y los riesgos y beneficios derivados; velará por el respeto a la confidencialidad y, también, por la trazabilidad de las muestras, todo lo cual debe llevarse a cabo sin que, en ningún caso, represente censura a la actividad investigadora.

$\mathrm{El}$ artículo 12 de la LIB establece el carácter preceptivo y vinculante del informe emitido por el Comité de Ética de la Investigación, de forma que ningún proyecto de investigación podrá autorizarse ni desarrollarse sin este previo y pre-

${ }^{28}$ Diversas leyes españolas y documentos supranacionales se refieren a Comités de Éticas o Bioética o a Comisiones asesoras semejantes. Entre otras, la Ley 14/2006, de 26 de mayo, de técnicas de reproducción asistida; el Real Decreto 223/2004, de 6 de febrero, por el que se regulan los ensayos clínicos con medicamentos; el Real Decreto 1201/2005, de 10 de octubre, para la protección de animales utilizados en experimentación y otros fines científicos; la Declaración Internacional sobre Datos genéticos Humanos; y la Declaración Universal sobre Bioética y Derechos Humanos. 
ceptivo informe favorable. La naturaleza vinculante del informe del Comité resulta compleja por cuanto limita la libertad de investigación y los derechos a la investigación, creación y producción científica sin que parezcan establecerse garantías suficientes. La intervención del Comité resulta decisoria en otros momentos del proceso investigador (entre otros, art. 14, 16, 17, 18, 21, 25 o 62) e incluso posee competencia para instar la suspensión cautelar de una investigación en los casos - dice el artículo 17- en que no se hayan observado los requisitos establecidos en la LIB y la suspensión sea necesaria para proteger los derechos de los ciudadanos. Aunque la LIB no establece el procedimiento, las resoluciones de los Comités de Ética que tengan carácter vinculante o limiten derechos deben poder ser recurridas con todas las garantías, pues en otro caso los derechos de los investigadores y, quizá, también de los pacientes y sujetos participantes en una investigación, quedarían sin garantía.

Uno de los aspectos más conflictivos que actualmente rodean la existencia de los Comités de Ética es, precisamente, la discrepancia que parece existir entre su denominación y sus iniciales objetivos (colaborar con los profesionales en la resolución de problemas concretos en la práctica médica y en la investigación conforme a criterios éticos) y sus actuales funciones que cada vez están más vinculadas al Derecho, lo cual les convierte en órganos de control jurídico sin que - en ocasiones - su estructura y funcionamiento se ajuste estrictamente a estos nuevos cometidos.

6) Principio de precaución. Se ha incluido en este artículo 2, en su apartado f), el denominado principio de precaución que pretender prevenir y, en su caso, evitar posibles riesgos que pudieran derivase de las actuaciones investigadoras para la vida y la salud de las personas. Este principio que tiene su origen en el ámbito de los problemas medioambientale ${ }^{29}$ ha encontrado ubicación también en las actuaciones biomédicas. Ha tenido un amplio desarrollo en el ámbito de la Unión Europea, donde, en virtud del Tratado de Maastricht, el segundo apartado del artículo $130 \mathrm{R}$ del Tratado CE, dispone que la política de la Comunidad en el ámbito del medio ambiente «... se basará en los principios de cautela y de acción preventiva». El principio de precaución, como se ha señalado anteriormente, desborda actualmente el campo medioambiental e irradia en la política de consumo, de salud humana, animal o vegetal.

29 En Alemania, en la década de los ochenta, este principio aparece vinculado a la protección del medio ambiente (Vorsorgeprinzip y Vorsorge); la Conferencia de las Naciones Unidas sobre Medio Ambiente (CNUMAD), celebrada en Río de Janeiro en 1992, incluyo el criterio de precaución en el principio 15 de la Declaración que se adoptó. 
El Consejo solicitó a la Comisión Europea, en su Resolución de 13 de abril de 1999, que elaborase unas líneas directrices con vistas a la aplicación de este principio que, sin embargo, no había recibido una definición clara. La Comisión cumplió con esta petición a través de una Comunicación en la que manifiesta que puede invocarse este principio cuando exista una situación potencialmente peligrosa derivada de un producto, de un procedimiento o de un fenómeno, constatada mediante una evaluación científica y objetiva aunque la misma no permita determinar el riesgo con certeza. Así pues, la apelación al principio de precaución se ubica en el ámbito general del análisis de riesgos (que abarca, aparte de la determinación del riesgo, la gestión y la comunicación del mismo), y más específicamente en el marco de la gestión del riesgo vinculada a la toma de decisiones.

Resulta de importancia destacar que el principio de precaución no puede justificar la adopción de decisiones arbitrarias y que, por tanto, su aplicación solo puede ir seguida de la constatación de tres condiciones previas: a) identificación de los efectos potencialmente negativos; b) evaluación de los datos científicos disponibles; y c) determinación del grado de incertidumbre científica. El Consejo Europeo de Niza (diciembre, 2000) precisó este concepto de manera que cuando, tras la oportuna evaluación, no es posible concluir sobre un cierto nivel de riesgo, las medidas de gestión del riesgo deben ser tomadas sobre la base de una apreciación política que determine el nivel de protección buscado. Las medidas deben ser las menos restrictivas para los intercambios comerciales, respetar el principio de proporcionalidad y ser revisadas frecuentemente de acuerdo con la evolución de los conocimientos científicos.

7) Principio de evaluación de la actividad investigadora. Por este principio la LIB articula mecanismos de control de la actividad investigadora, control que tanto se proyecta hacia los resultados como en relación con los medios y sistemas de llevar a cabo dicha investigación. La Ley contiene previsiones específicas sobre la evaluación de la actividad investigadora a lo largo de su articulado, en especial, en el Capítulo II, del Título II. Como en el caso de la actuación de los Comités de Ética a los que antes se ha hecho referencia, la mayor dificultad de la evaluación de la actividad investigadora en llevarla a cabo sin vulnerar el contenido esencial de la libertad de investigación.

\subsection{Libertad e igualdad: los principios ausentes}

A pesar de su extensión y de la importancia de su contenido, el artículo 2 comentado, ya se interprete en clave de "principios» (como creo que es lo correcto) 
o en clave de "garantías» (como parece hacer el propio precepto), es deudor de dos principios-derechos esenciales: la libertad individual ${ }^{30} \mathrm{y}$ la igualdad.

La omisión, deliberada o no, del principio de libertad en este inicial precepto de la Ley es un dato negativo que no queda paliado por la importancia de la regulación posterior — sin duda, pormenorizada - que la Ley contiene en orden a la obtención del consentimiento informado basado en la autonomía de la persona y a otros derechos del paciente. La libertad individual es el fundamento del nuevo Bioderecho y debería figurar entre los principios rectores de la Ley y, quizá, también debería haber sido mencionado en el artículo 1.1 al definir el objeto de la Ley.

La clásica relación médico-paciente - extensiva actualmente a la mantenida por el investigador y el sujeto participante en una investigación- en la que el primero gozaba de una situación de clara preeminencia en base a sus mayores conocimientos ha sido progresivamente sustituida por una relación basada en la libre decisión del sujeto. Este reconocimiento de la libertad individual se ha plasmado no sólo en la capacidad de decisión del sujeto articulada a través del consentimiento informado, sino en otros aspectos como en su capacidad para negarse a recibir un tratamiento; en la posibilidad de aceptar su voluntad anticipada para los casos en los que no pueda ya emitir su opinión o, incluso, en el denominado derecho a no saber ${ }^{31}$. No es fácil encontrar justificación a la ausencia en esta importante norma de una mención expresa y clara de reconocimiento de la libertad individual como fundamento de las nuevas leyes biomédicas.

Tampoco hay una mención expresa a la igualdad como principio rector de la Ley de Investigación Biomédica ${ }^{32}$ pero, en este caso, el artículo 6, establece la prohibición de discriminación para casos concretos aunque no como principio general. Según este precepto, nadie podrá ser discriminado por sus características genéticas, ni por su negativa a someterse a un análisis genético o a prestar su consentimiento para participar en una investigación biomédica o para donar ma-

30 Vengo defendiendo la mayor corrección del uso del término libertad y no del de autonomía que es más frecuente en textos internacionales y también en la legislación española sobre la materia.

31 Posibilidades todas ellas incluidas ya en la Ley 41/2002, de 14 de noviembre, básica reguladora de la autonomía del paciente y de derechos y obligaciones en materia de información y documentación clínica; en la legislación de las Comunidades Autónomas sobre el mismo tema y en documentos internacionales de la relevancia del Convenio sobre Biomedicina y Derechos Humanos.

32 Sí hay referencias a la igualdad en la asistencia sanitaria y prestaciones de salud en la Ley 16/2003, de 28 de mayo, de Cohesión y Calidad del Sistema Nacional de Salud (Preámbulo y arts. 1 y 2 a) entre otros). 
teriales biológicos. Una mención a la igualdad en el acceso a los análisis genéticos, contenida en el artículo 45 a) de la Ley, agotan las referencias. En realidad, la prohibición de discriminación se predica respecto de asuntos en los que la libertad individual es soberana, por este motivo la ausencia tanto de una como de otra es especialmente relevante aunque la Constitución supla esta ausencia ya que tanto la libertad individual como la igualdad están ampliamente reconocidas y garantizadas en el Texto Fundamental.

El término discriminar significa separar, distinguir, o diferenciar una cosa de otra; sólo en su aplicación e interpretación jurídica se identifica con trato diferente dado a una persona o grupo por motivos de raza, religión, condición social, personal, sexo y más recientemente características genéticas o salud. La discriminación viene siendo definida, pues, en el ámbito jurídico, como sinónimo de trato desigual desfavorable carente de justificación razonable y prohibido por el Derecho. Cabe, por tanto, que un trato «diferente» no resulte contrario a la igualdad y, por tanto, no sea discriminatorio. El concepto de razonabilidad, identificable en cada caso, permite tolerar la diferenciación y la justifica. La construcción teórica del parámetro de "diferenciación razonable» no es tarea fácil ni para el legislador (nacional y supranacional) ni para el juez, pero ha permitido avanzar en la tutela de muy diferentes situaciones que requerían cierto trato diferenciado y, al contrario, en la equiparación de otras que históricamente venían recibiendo un trato nítidamente discriminatorio.

Tampoco incluye este Ley de Investigación Biomédica referencia alguna a la prohibición de estigmatización, término que viene siendo incorporado recientemente a relevantes documentos supranacionales. Tal es el caso del artículo 11 de la Declaración Universal de Bioética y Derechos Humanos de la UNESCO que lo incluye junto con el principio de no discriminación.

Estigma es una marca o señal con la que se pretende identificar negativamente a una persona. Si bien originariamente el estigma es una marca o señal física en el cuerpo, actualmente la estigmatización alude mucho más frecuentemente a una característica física, psíquica o moral de la persona por la cual ésta sufre el rechazo de la sociedad y/o del poder público. Actualmente, pues, el concepto de estigmatización es sobre todo un concepto social y se diferencia de la discriminación en que ésta representa siempre un trato desfavorable prohibido por el Derecho, mientras que la estigmatización es un daño a la persona, en su valoración como ser humano con independencia de lo que pueda establecer el Derecho; es el propio rechazo del sujeto, su consideración como una persona inferior, el que origina el daño sin necesidad de que concurra un acto público concreto o exista una legislación vulneradora de la igualdad. Así, por ejemplo, una persona puede estar estigmatizada en su entorno sin que, sin embargo, exista ni 
legislación ni actos concretos que permitan acreditar que sufre discriminación. Aunque obviamente los conceptos de discriminación y estigmatización pueden llegar a ser cercanos, estimo que hay diferencias entre ellos que permiten distinguirlos nítidamente. La conveniencia de unir en las normas que regulan aspectos biomédicos, los conceptos de estigmatización y discriminación radica en que así se cubren los dos grandes ámbitos a través de los que las personas pueden sufrir rechazo y marginación: los actos discriminatorios (legislativos o de otra naturaleza) y la estigmatización como repudio social de una persona por sus características personales, genéticas o de salud.

Title

THE FREEDOM OF CREATION AND SCIENTIFIC PRODUCTION: SPECIAL REFERENCE TO THE LAW OF BIOMEDICAL RESEARCH

\title{
Summary \\ I. THE FUNDAMENTAL RIGHT TO RESEARCH AND SCIEN- TIFIC PRODUCTION. II. GUARANTEES AND LIMITS OF SCIENTIFIC RESEARCH. III. THE BIOMEDICAL RESEARCH LAW AS ORDINARY LAW. IV. THE BIOMEDICAL RESEARCH LAW. 1. OBJECT AND SCOPE OF APPLICATION. 2. PRINCI- PLES OF THE BIOMEDICAL RESEARCH LAN. 3. FREEDOM AND EQUALITY: THE ABSENT PRINCIPLES
}

\begin{abstract}
Resumen
No hay en la Constitución española una referencia directa y explícita a la investigación biomédica ni encontramos tampoco en el Texto Fundamental referencias a otros problemas derivados de estas nuevas tecnologías. Sí contiene la Constitución, sin embargo, referencias directas a la investigación en general (arts. 44.2, 148.1.17 y 149.1.15); y ha reconocido, como derecho fundamental, la producción y creación científica en el artículo 20.1b). En este artículo se defiende que la libertad de investigación forma parte del contenido esencial del derecho fundamental a la producción y creación científica. Se analizan también los principios que integra la Ley de Investigación Biomédica y se cuestiona la ausencia en esta Ley de referencias explícitas al dereco a la libertad y a la igualdad.
\end{abstract}




\begin{abstract}
The spanish Constitution does not contain a direct and explicit reference to biomedical research; neither can we find in the Constitution reference to other problems regarding new biotechnologies. However, the Constitution includes direct references to a general freedom of research (Articles 44.2, 148.1.17 and 149.1.15); and it recognizes as a fndamental right scientific creation and production in the Article 20.1b). This work establishes freedom of research as part of the essential contents of the fundamental right to scientific creation and production. The paper also analyzes the principles contained in the Biomedical Research Law. The absence in $\mathrm{t}$ his Law of explicit references to freedom and equality of the individual regarding biomedical applications is criticized.

Palabras clave

Derecho fundamental - Libertad de investigación científica - Ley orgánica - Libertad e igualdad - Censura previa.
\end{abstract}

\title{
Key words
}

Fundamental Right - Freedom of scientific research - Organic Law Freedom and equality - Censorship. 